\title{
Benchmarking em empresas de construção civil: identificação das melhores práticas
}

\author{
Andrade, F. K. G. \\ Escola Politécnica de Pernambuco \\ Universidade de Pernambuco \\ 50.720-001 - Recife, Brasil \\ fabiakamilly@hotmail.com
}

\author{
Lordsleem Jr., A. C. \\ Escola Politécnica de Pernambuco \\ Universidade de Pernambuco \\ 50.720-001 - Recife, Brasil
}

\begin{abstract}
Resumo Uma tendência dos dias atuais é a medição da qualidade e produtividade através de indicadores de desempenho, que se referem ao comportamento do processo ou produto em relação a determinadas variáveis: custo, lucro, desperdício, entre outras. Para definir estratégias de qualidade, os indicadores de desempenho de várias construtoras são avaliados e, posteriormente, é realizada uma análise comparativa dos resultados obtidos. A esse método que permite controlar processos críticos e apresentar possibilidades de melhorias através da comparação de resultados, dá-se o nome de benchmarking. $O$ presente artigo vai ao encontro desse contexto, analisa e discute, 10 (dez) indicadores de desempenho, a partir de uma experiência de benchmarking realizada por empresas da construção de edifícios, cuja metodologia contemplou o desenvolvimento de check lists de caracterização, a coleta de dados e a discussão das melhores práticas identificadas num grupo de 12 (doze) construtoras na cidade de Recife/PE.
\end{abstract}

\footnotetext{
Abstract A trend today is to measure the quality and productivity through performance indicators, which refer to the behavior of the process or product in relation to certain variables: cost, profit, waste, among others. To define strategies for quality, performance indicators are evaluated for various construction and is later performed a comparative analysis of the results. In this method to control critical processes and present possibilities for improvement by comparing the results, gives the name of benchmarking. This article is going to meet this context, analysis and discussion, 10 (ten) performance indicators, from an experience of benchmarking carried out by companies in the construction of buildings, whose methodology has seen the development of checklists of characterization, collection data and discussion of best practices identified in a group of 12 (twelve) building in the city of Recife / PE.
} 


\section{Introdução}

Muitas empresas ainda utilizam sistemas de medição de desempenho tradicionais, nos quais predominam indicadores de caráter contábil, que somente indicam resultados de ações já realizadas (MASKELL et al., 1991 apud COSTA, 2003, p.13).

Essas medidas não focam a visão estratégica, não otimizam a tomada de decisão e oferecem pouca flexibilidade para a solução dos problemas. Além disso, pouco se sabe sobre a satisfação de clientes e o desempenho dos concorrentes. Desse modo, busca-se uma padronização e não a melhoria contínua (NELLY, 1990 apud COSTA, 2003, p.13).

Na busca pelo aperfeiçoamento contínuo da gestão da qualidade, as empresas de construção civil têm aderido à medição de desempenho através de indicadores. Esta prática é relativamente recente, tendo recebido forte impulso pela implantação e certificação de sistemas de gestão da qualidade pelas empresas construtoras.

A adoção dos indicadores de desempenho promove o conhecimento do desempenho das empresas e quando inseridos num processo colaborativo propicia a avaliação comparativa dos resultados entre as empresas de construção civil e, a partir daí, uma identificação das melhores práticas.

Benchmarking é a denominação dada a essa avaliação comparativa para busca das melhores práticas na indústria, que conduzem ao desempenho superior. É visto como um processo positivo e proativo por meio do qual uma empresa examina como a outra realiza uma função específica a fim de melhorar a realização da mesma ou de uma função semelhante.

Tomando como referência uma experiência de benchmarking com 12 (doze) empresas de construção civil localizadas em Recife (PE), 10 (dez) indicadores de desempenho puderam ser comparados e analisados, a fim de identificar as práticas que levaram determinada empresa a se destacar num dado indicador.

Os 10 (dez) indicadores selecionados foram: absenteísmo, consumo de argamassa industrializada, geração de resíduos de placas cerâmicas, boas práticas em saúde e segurança do trabalho, satisfação do cliente (usuário), tempo médio de atendimento, custo dos serviços de assistência técnica, inadimplência, ritmo de vendas e geração de resíduos de tijolos/blocos; todos baseados no sistema INDICON - Projeto de concepção e implantação do sistema de benchmarking, idealizado pelo grupo de pesquisa POLITECH (Tecnologia e Gestão na Construção de Edifícios), trabalho esse coordenado pelo Sindicato da Indústria da ConstruçãoCivil do Estado de Pernambuco - SINDUSCON/PE.

Estes indicadores de desempenho serão apresentados e discutidos, a seguir, a fim de identificar as práticas adotadas pela empresa que obteve o melhor resultado.

\section{Objetivo}

Identificar às melhores práticas de indicadores de desempenho, possibilitando a geração de valores de referência para o setor, dando subsídio para a promoção de ações de melhoria contínua e aprendizado.

\section{Metodologia}

A pesquisa foi desenvolvida no decorrer de um ano e divida em cinco etapas:

- Etapa 1: levantamento bibliográfico (normas, artigos, teses, dissertações, etc);

- Etapa 2: levantamento de dados e definição do método de caracterização do benchmarking;

- Etapa 3: análise dos indicadores de desempenho e realização de coleta de dados;

- Etapa 4: identificação e caracterização das melhores práticas;

- Etapa 5: diretrizes para a adoção das melhores práticas.

Serão discutidas as etapas $2,3 \mathrm{e} 4$, visto que a etapa 1 já foi detalhada no item 1 e a etapa 5 detalhada no item 4 .

\section{Método de apropriação de dados}

Inicialmente, foram coletados os valores mínimo, máximo e de benchmarking das 08 (oito) empresas de construção civil que se destacaram nos indicadores analisados. A Figura 1 apresenta os valores obtidos, junto com a identificação da empresa que obteve estes resultados, considerados melhores em comparação com as demais. 


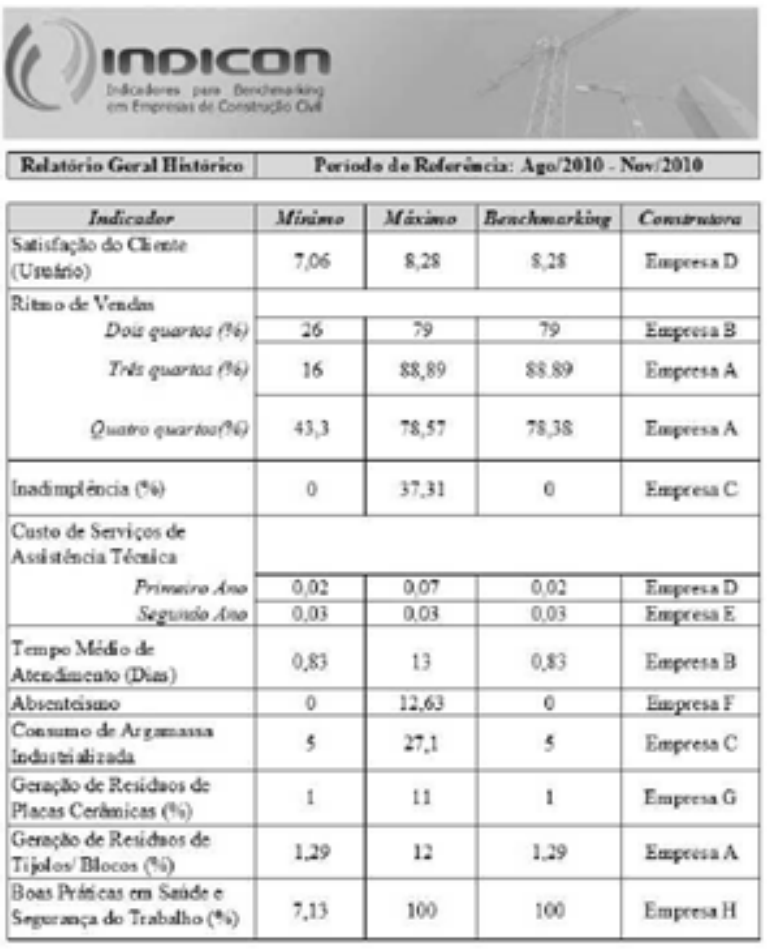

Fig 1. Valores mínimo, máximo e de benchmarking

Os resultados apresentados na Figura 1 foram coletados, mensalmente, no período de Agosto/2010 a Novembro/2010 através do site do INDICON. Eles representaram os melhores valores obtidos nesse período, sendo analisados, posteriormente, por indicador, a fim de identificar as condições que levaram determinada empresa a obter os resultados.

\section{Método de caracterização do bench- marking}

Para a identificação das melhores práticas adotadas nas oito empresas estudadas, foram elaborados para cada um dos indicadores questionários de caracterização do benchmarking. Esses questionários continham algumas perguntas - delineadas a partir das possíveis variáveis do resultado - que foram aplicadas em entrevistas pessoalmente, realizadas com os responsáveis dos setores envolvidos nas construtoras.

\section{Análise dos indicadores de desempe- nhos e discussão dos resultados}

O INDICON é um sistema de medição via internet, que consiste na concepção, no desenvolvimento e na implantação de um sistema de indicadores de desempenho para benchmarking em empresas de construção civil.
Ao acessar o link <www.indicon.dominiotemporario.com>, a empresa pode fazer o login, preenchendo os espaços de usuário e senha localizados na parte direita e superior da tela para inserção de dados.

\subsection{Estilos}

Conceitua-se absenteísmo como sendo o índice que reflete a percentagem do tempo não trabalhado em decorrência das ausências em relação ao volume de atividade esperada ou planejada (CHIAVENATO, 2004).

Este indicador foi selecionado, principalmente, devido à influência no andamento da obra, na produtividade dos funcionários e nos custos de produção (NOGUEIRA,1982; AZEVEDO, 1982). A partir do controle das faltas, há ganhos de produtividade dos funcionários, e os custos incorridos por horas não trabalhadas são minimizados, refletindo no custo total do empreendimento.

O absenteísmo considerado na pesquisa envolveu os trabalhadores de campo, sendo considerada como falta qualquer tipo de ausência não programada, justificada ou não.

$\mathrm{Na}$ entrevista, realizada com a empresa $\mathrm{F}$ que obteve um índice zero de faltas num mês, foram levantados e discutidos, aspectos que poderiam influenciar os resultados obtidos deste indicador, sendo o principal deles o estabelecimento, pelo RH, de uma política voltada à satisfação completa de seus empregados.

Essa política caracterizou-se, principalmente, pela motivação dos funcionários oriunda da possibilidade de promoção. Na entrevista, foram levantadas, inúmeras vezes, as chances oferecidas àqueles funcionários que se mostram dispostos: estes são treinados por profissionais mais qualificados no próprio canteiro de obras, no horário de expediente, para adequar-se às novas posições oferecidas e, consequentemente, com melhor remuneração. O mesmo acontece para os estagiários de engenharia civil, que têm a possibilidade de ingressar num programa de trainees, antes de assumirem um empreendimento como engenheiros.

Os funcionários, em geral, são aproveitados para outros empreendimentos, devido à escassez dos mesmos frente ao "boom" da construção civil. Segundo os gerentes entrevistados, é muito difícil um funcionário ser desligado da empresa, justamente pela necessidade do mesmo nos empreendimentos. Por isso, é tão importante manter o mesmo satisfeito com a construtora.

Havendo necessidade de advertência, o empregado é advertido verbalmente e por escrito, antes de ocorrer um desligamento da empresa por justa causa, não necessariamente nesta ordem. 
Além da possibilidade de promoção, há um incentivo de produtividade, que se resume, basicamente, a seguinte frase: produz mais, ganha mais. Se a obra encontra-se adiantada em relação ao cronograma, são feitas premiações de cestas básicas aos trabalhadores que se destacam.

O emprego de mulheres apenas em atividades técnicas também conta como vantagem na redução do absenteísmo, já que, segundo Reis et al. (2003 apud DALL'INHA, 2006, p.27), as mulheres se afastam mais que os homens, devido a dupla atividade: no trabalho e no lar.

Uma prática bastante positiva para reduzir o absenteísmo e identificada na empresa $\mathrm{F}$ foi o estabelecimento de um tempo, entre 10 e 15 minutos antes das atividades, para comunicação com os funcionários quanto à pontualidade, posicionamento da chefia, ausências e necessidade de estender o expediente em caso de concretagem, por exemplo.

Constatou-se que as empresas envolvidas com as políticas de RH possuem maior influência sobre seus funcionários. Elas provocam um grande efeito positivo sobre a mão-de-obra e os resultados obtidos por meio deles (DALL'INHA, 2006).

\subsection{Consumo de argamassa industrializada}

As empresas de construção civil poderiam obter ganhos de eficiência no uso da argamassa industrializada, realizando uma análise nos processos envolvidos, que compreendem desde o recebimento até a aplicação do material (OLIVEIRA, 2006). Daí, a importância de se analisar este indicador de desempenho.

A argamassa industrializada monitorada na pesquisa era utilizada no assentamento de tijolos/blocos da alvenaria de vedação.

A empresa que obteve o melhor resultado, segundo a Figura 1, foi à empresa $\mathrm{C}$, dando-se pela maior atenção no recebimento de materiais e estocagem dos mesmos.

Apesar da descarga manual, que poderia ser evitada com o simples uso de carrinhos porta-pallets, os sacos de argamassa industrializada foram descarregados diretamente no depósito, após uma inspeção realizada por amostragem. Essa prática evita o estoque intermediário e os deslocamentos posteriores, evitando qualquer dano nos sacos com os transportes e perda de produtividade de alguns funcionários para efetuar esses deslocamentos (LORDSLEEM, 2009; PINHO, 2009).

Além disso, a inspeção no momento do recebimento dos sacos evita tanto a geração de resíduos quanto custos do material extra. Na empresa C, a inspeção foi feita por amostragem, sendo analisados, os aspectos enumerados na
Tabela 2 no Item 2. Caso os sacos apresentassem algum dano durante a inspeção que pudesse prejudicar a qualidade do material, como exposição à água e/ou presença de pedregulhos, estes seriam segregados para troca com o próprio fornecedor.

A NBR 7200 (ABNT, 1998) diz que os materiais ensacados, após recebimento, devem ser armazenados em local fechado, protegido da umidade, sobre estrado ou assoalho de madeira, não tendo contato com a parede e ordenados segundo a data de validade para que sejam consumidos dentro do prazo. Se esta norma for realmente seguida, como foi o caso da empresa $\mathrm{C}$, os ganhos de material e de organização são consideráveis.

No preparo da argamassa, cada pavimento da obra monitorada possuía um cartão de controle da quantidade de sacos destinados ao mesmo. Esse controle do material era realizado pelo estagiário de engenharia civil, que detinha autonomia sobre o estoque. No caso da argamassa industrializada, o preparo em locais variáveis é favorecido, permitindo menores solicitações de transporte e mão-de-obra, e otimização do sistema de transporte vertical, com utilização fora dos horários de pico (OLIVEIRA, 2006).

O uso de ferramentas como a desempenadeira de madeira e bisnaga no preenchimento das juntas horizontais e verticais, respectivamente, contribuiu para maior aproveitamento do material e limpeza do local. Já o uso de misturadores, como a argamassadeira, facilitou o deslocamento da argamassa por apenas um profissional em todo o canteiro.

O que se buscou na empresa $\mathrm{C}$ foi um aperfeiçoamento na logística do canteiro de obras, bem como algumas inovações no trabalho com a argamassa, como o uso de argamassadeira e ferramentas mais precisas.

\subsection{Geração de resíduos de placas cerâmicas}

A construção civil tem se tornado a campeã em geração de resíduos sólidos nas grandes cidades, superando até mesmo a produção de lixo doméstico. Dentre os materiais mais susceptíveis ao desperdício encontramse as placas cerâmicas, que, juntamente com outros materiais, como plástico, concreto e metais, representam cerca de $6 \%$ do total de entulho gerado no canteiro de obras (CAMARGO, 1995).

Os resíduos de placas cerâmicas considerados foram àqueles provenientes do revestimento interno.

Assim como a empresa $\mathrm{C}$ controlou as quantidades de sacos de argamassa por apartamento no indicador "con- 
sumo de argamassa industrializada", a empresa G procurou controlar a quantidade de caixas de placas cerâmicas por apartamento. Essa quantidade foi previamente estudada no projeto arquitetônico e estabelecida junto ao estagiário de engenharia civil, que controlava as entradas e saídas do material por apartamento.

A aplicação da argamassa na obra monitorada deu-se tanto na placa quanto no piso ou parede para garantir maior aderência da mesma, evitando descolamentos futuros.

Quanto ao recebimento do material, eram realizadas verificações de tonalidade, metragem, planeza, espessura, ortogonalidade, pesagem, entre outros aspectos no lote de inspeção. Essa inspeção tinha uma duração média de 10 a 15 minutos por caixa.

Para facilitar o trabalho com essas placas, máquinas de corte e furação rápidas em cada pavimento compunham as ferramentas dos trabalhadores, permitindo maior precisão e diminuição do número de peças danificadas pelo corte inadequado, como por exemplo, a serra mármore.

Este indicador de desempenho está intimamente atrelado à prática de produção mais limpa, que não preocupase apenas com ganhos de eficiência construtiva, mas com o conceito de sustentabilidade.

\subsection{Boas práticas em saúde e segurança no trabalho}

A construção civil é, hoje, um dos setores de atividade econômica que mais absorve mão-de-obra e que mais gera acidentes de trabalho (LIMA; VALCÁRCEL; DIAS, 2005). Segundo estimativas da OIT (Organização Internacional do Trabalho), dos aproximadamente 355 mil acidentes mortais que acontecem anualmente no mundo, pelo menos 60 mil ocorrem em obras de construção.

Os acidentes de trabalho, geralmente, são decorrentes de três tipos de situações: aqueles que acontecem no exercício do trabalho, típicos; aqueles que acontecem no percurso entre residência e o trabalho, trajeto; aqueles devidos a doenças profissionais, doenças no trabalho (LIMA; VALCÁRCEL; DIAS, 2005).

Dentre as práticas que contribuíam para redução dos acidentes típicos, tem-se o treinamento da mão-de-obra. De essencial importância para a percepção dos riscos de acidentes pelos funcionários, o treinamento caracterizouse pelo uso de DDS (Diálogo Diária de Segurança).

A empresa $H$ também possuía um indicador interno atrelado a cada funcionário através de fichas individuais, que continham todas as informações necessárias para sa- úde e segurança do mesmo. Nesta ficha consta, por exemplo: acompanhamento do tempo mínimo de treinamento mensal, que era de 3 horas; e a situação do equipamento de proteção individual daquele funcionário específico, ou seja, se o equipamento estava adequado pra uso ou se necessitava de troca.

A limpeza da obra também era item analisado, passando por uma auditoria externa, uma vez ao mês. Em caso de inadequação de limpeza, o engenheiro de segurança e o técnico eram advertidos, devendo ter corrigido o problema na auditoria seguinte.

Simulações de emergência, estabelecimento de rota de fuga e ponto de encontro, técnica de segurança com curso de primeiros socorros, zonas de perigo sinalizadas e uma Planilha de Identificação de Perigos e Avaliação de Riscos (PIPAR) caracterizaram o indicador nesta construtora.

A experiência da empresa $\mathrm{H}$ confirmou que a prevenção de acidentes na indústria da construção deve priorizar treinamento dos trabalhadores para melhor percepção dos riscos, além de uma equipe técnica capacitada, que saiba monitorar o desempenho do indicador.

\subsection{Satisfação do cliente (usuário)}

Por muitos anos, os conceitos de qualidade ficaram restritos à área da produção. Hoje, eles são aplicados cada vez mais aos serviços agregados ao produto, em busca da satisfação total do cliente. Dentre os principais serviços, encontra-se a assistência técnica (RESENDE; MELHADO; MEDEIROS, 2002).

A empresa que obteve o melhor resultado neste indicador, de acordo com a Figura 1, foi a empresa D, observando-se que o resultado obtido pela mesma deu-se pela maior atenção, antes e durante, à entrega do imóvel ao cliente.

Antes da entrega, foi realizada uma vistoria interna, que consiste na avaliação da obra por um cliente interno que, preferencialmente, não tenha participado da produção e seja membro da área de assistência técnica, pois esses, geralmente, têm uma visão crítica para a identificação de defeitos e têm conhecimentos dos defeitos potenciais, uma vez que atendem os clientes insatisfeitos (SOUZA, 1997 apud RESENDE; MELHADO; MEDEIROS, 2002).

A vistoria interna na empresa $\mathrm{D}$ era bastante criteriosa e efetuada não por um funcionário da assistência, mas por um engenheiro da construtora, que não estava envolvido com a obra em questão. Qualquer inadequação apontada, já era corrigida antes da entrega ao cliente. 
Já na vistoria com o cliente, realizada por um funcionário da assistência técnica no ato da entrega do imóvel, todos os itens analisados na vistoria interna eram novamente apontados e com o mesmo critério. Em média, cada entrega de apartamento durava 02 (duas) horas, sendo realizadas no máximo 02 (duas) entregas ao dia, para maior atenção ao cliente. Ao término da vistoria, a entrega era formalizada através da assinatura do termo de vistoria do imóvel e do termo de recebimento do imóvel, visando atender às prescrições contidas no Código de Defesa do Consumidor.

A relação entre a empresa e seus clientes era estabelecida ao longo da edificação com reuniões mensais. Nessas reuniões, os clientes eram informados do estágio em que a obra se encontrava, prazos e discussão de intenções no condomínio ao término da obra, como indicação de administradoras pela empresa.

Em caso de falhas no uso do imóvel, o cliente procedia com uma solicitação de vistoria técnica, para checagem de deferimento ou indeferimento. Em caso de deferimento, a empresa prosseguia com o conserto. Em caso de indeferimento, era cobrada uma taxa de $\mathrm{R} \$ 150,00$ pelo serviço.

A partir dessas vistorias, a empresa $\mathrm{D}$ tinha o acesso às principais patologias encontradas no uso da edificação, que permitiam que esta fizesse um diagrama de causaefeito de falhas, visando à minimização em empreendimentos futuros.

Souza (1997) afirma que a identificação dos fatores que determinam o grau de satisfação dos clientes, ocorre com o acompanhamento do comportamento dos produtos após a entrega, principalmente através da análise dos dados fornecidos pela a assistência técnica.

Assim, as práticas identificadas na construtora $\mathrm{D}$, para maior satisfação de seus clientes, deu-se pelo diálogo aberto nas vistorias e retroalimentação do sistema de produção pela prevenção de patologias, através do uso de um diagrama de causa-efeito das falhas já ocorridas.

\subsection{Tempo médio de atendimento}

O Código Civil prevê que o construtor tem responsabilidade pela solidez da obra e por vícios ocultos que se manifestam somente após o período de uso. Ciente disso, toda construtora deve possuir procedimentos padronizados a serem seguidos para a realização dos serviços de assistência técnica (PICCHI, 1993; SOUZA, 1997 apud RESENDE; MELHADO; MEDEIROS, 2002).

As práticas que puderam ser identificadas na entrevista com a empresa B, que obteve o melhor resultado segundo a Figura 1, foram à existência de uma equipe voltada apenas para o recebimento das solicitações, composta por 04 (quatro) funcionários, e a realização da vistoria pelo próprio supervisor da assistência técnica.

Além disso, continha, no manual do proprietário, tanto o contato de fornecedores e da assistência técnica da construtora, quanto à descrição do procedimento a ser seguido pelo cliente para efetuar uma solicitação.

As solicitações podiam ser feitas pela internet ou pelo telefone, possuindo um prazo de resposta de até 72 horas.

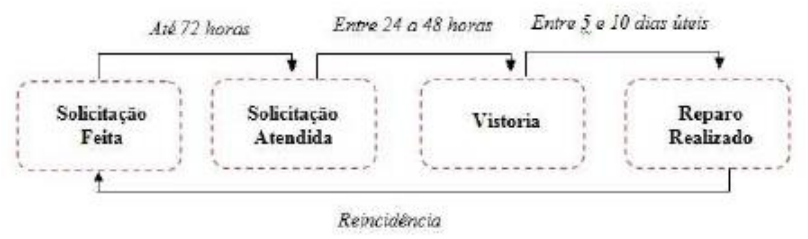

Verifica-se que, apesar da empresa B apresentar um baixo tempo médio de resposta entre a solicitação inicial e a solicitação final, os demais tempos ainda continuam elevados, se considerado o tempo total para a solução do problema.

A realização do serviço deve ser eficiente, uma vez que o final do processo de uma prestação de serviço, no caso o término da realização do reparo, é muito mais importante do que o começo do processo, no caso o atendimento a solicitação ao cliente (Chase; Dasu, 2001 apud RESENDE; MELHADO; MEDEIROS, 2002).

Esses autores argumentam que o final é o que fica na lembrança do cliente, uma vez que as pessoas possuem uma preferência inata pela melhoria. Dessa forma, esses mesmos autores afirmam que os reparos devem ser executados em um único estágio, uma vez que as experiências negativas parecem mais longas quando fracionadas em segmentos.

\subsection{Custo dos serviços de assistência técnica}

Segundo Resende, Melhado e Medeiros (2002), as principais funções da assistência técnica são: o atendimento às reclamações de clientes, a retroalimentação do sistema de produção e a apropriação de custos dos problemas patológicos.

Esta última pode identificar as principais oportunidades para a redução dos custos, da insatisfação do consumidor e servir de estímulo para o aperfeiçoamento tecnológico da empresa (JURAN, 1991 apud RESENDE; MELHADO; MEDEIROS, 2002). 
Este indicador de desempenho apresentou dois resultados de benchmarking: um referente ao primeiro ano após a entrega do empreendimento, e outro, referente ao segundo ano. Para cada um desses resultados, a Figura 02 indica uma empresa de construção específica.

Um dos fatores que mais interferem nos custos de assistência técnica é a utilização incorreta do manual do proprietário, disponibilizado ao cliente no momento de entrega do imóvel. Este manual contém informações úteis com relação ao material empregado, manutenção e uso do edifício.

Muitas vezes, o cliente contrata algum serviço externo para a realização de reparos, sem o conhecimento da construtora e sem consulta ao manual do proprietário, o qual acentua ainda mais as patologias existentes.

É importante que a construtora, no momento de entrega do imóvel, informe ao seu cliente todas as informações contidas no manual do proprietário, bem como o procedimento a ser seguido pelo mesmo para efetuar as solicitações de vistorias. Essa prática evita custos futuros incorridos pelo uso ou reparação inadequada (Souza et al., 1994).

Sabendo a importância do uso correto do manual, o conteúdo presente no mesmo também pôde ser identificado como uma variável do indicador estudado.

Percebeu-se nas entrevistas realizadas com as construtoras que, ambas as empresas possuíam, praticamente, as mesmas informações no manual, salvo algumas particularidades, como por exemplo, a empresa D ofereceu o croqui do apartamento, o dimensionamento dos pesos admissíveis na estrutura e um item referente à mudança. Já a construtora $\mathrm{E}$, ofereceu a descrição dos fornecedores e as plantas da área privativa e área comum.

Notou-se também que a finalidade do levantamento dos custos de assistência técnica era a mesma para ambas as empresas, exceto pelo treinamento que a construtora $\mathrm{D}$ oferecia aos funcionários dos próximos empreendimentos, que era baseado nas principais patologias já encontradas nos serviços realizados.

A contribuição da assistência técnica das construtoras D e E se deu pela determinação da causa fundamental de cada manifestação patológica encontrada e da freqüência de ocorrência das mesmas, favorecendo seus resultados no indicador de desempenho estudado.

\subsection{Inadimplência}

A construção civil é um dos primeiros setores da indústria a sentir os reflexos da alta dos juros e a sofrer com a paralisação das atividades, que, por conseqüência, provoca queda no número de investimentos (CARDOSO, 2005).

Por estar mais vulnerável às oscilações da economia, o setor apresenta elevado risco de crédito, sendo relevante $o$ controle do número de inadimplentes entre seus clientes, a fim de evitar a falta de recursos para saudar os compromissos com as instituições financeiras.

Para que as empresas possam controlar o número de inadimplentes, o INDICON considerou como indicador de desempenho o índice de inadimplência, visando oferecer mecanismos de controle, a partir da identificação das melhores práticas.

$\mathrm{Na}$ entrevista, realizada com a gerente do departamento de vendas, foi levantado quais seriam os mecanismos para checagem de crédito dos seus clientes, podendo este critério ter influenciado o resultado obtido pela mesma. A resposta estava no perfil do cliente ao qual era oferecido o empreendimento, que, em geral, eram investidores ou indivíduos pertencentes à classe média alta.

Por possuir clientes de alto poder aquisitivo, aempresa $\mathrm{C}$ fez uso de uma carteira de clientes fiéis que, dificilmente, atrasou o pagamento das parcelas.

Apesar da vantagem, a construtora fez o uso de uma rotina de "cobrança prévia", efetuada 15 dias antes do vencimento, por meio de boleto bancário, lembrando aos seus clientes o compromisso assumido.

Quando acontecia algum atraso, o setor responsável pela cobrança não esperava mais de três dias para efetuála. A própria gerente de vendas era que entrava em contato com o cliente por telefone, procurando informações quanto ao possível não recebimento do boleto bancário.

Segundo a gerente entrevistada, a camuflagem na cobrança faz com que a empresa ganhe, ainda mais, a confiança, o respeito e a fidelização de seus clientes. Por isso, pouco foi investido no marketing de vendas do empreendimento monitorado, sendo a maior divulgação realizada pelo "boca a boca" dos mesmos.

Nota-se que a empresa $\mathrm{C}$ foi favorecida neste indicador pelo perfil de clientes aos quais são destinados os empreendimentos lançados, clientes estes de alto poder aquisitivo. No entanto, foi possível identificar as melhores práticas vivenciadas na empresa $\mathrm{C}$ e que podem oferecer, às demais construtoras, subsídios para a redução no índice de inadimplência, como a prática da cobrança prévia e da cobrança camuflada.

\subsection{Ritmos de vendas}


Dados do Sindicato da Indústria da Construção Civil do Estado de São Paulo (SINDUSCON-SP) mostraram que o setor da construção civil expandiu cerca de $8,8 \%$, em todo o país, no ano de 2010. Em Pernambuco, o mercado tem se mostrado tão vigoroso, que motivou não só o aumento da concorrência, mas o aperfeiçoamento no desempenho de seus departamentos.

O desempenho do processo comercial das 08 (oito) empresas que participaram da presente pesquisa pôde ser medido através do indicador ritmo de vendas. Este sinaliza o quanto uma construtora está sintonizada com os seus consumidores, fornecendo um produto ao gosto do cliente.

$\mathrm{O}$ indicador ritmo de vendas foi coletado para empreendimentos de 02 (dois) quartos, 03 (três) e 04 (quatro) quartos, tendo a empresa $\mathrm{B}$ se destacado no segmento dois quartos e a empresa A se destacando no segmento três e quatro quartos.

A descrição do empreendimento é fator essencial para o entendimento do ritmo de vendas do mesmo, pois este pode apresentar ou não os itens que determinam o fechamento de uma compra.

Analisando as áreas privativas dos dois empreendimentos monitorados, verificou-se que estes compreendem cerca de $60 \mathrm{~m} 2$, sendo considerados como apartamentos pequenos, e oferecendo boas condições de lazer, como por exemplo, piscina, playground e salão de festas.

Segundo reportagem do Jornal Hoje, quem ganha entre cinco e dez salários mínimos busca um novo tipo de imóvel: pequeno, mas com "mordomias". Assim, o fato das construtoras terem lançado os empreendimentos com estas características, pode ter contribuído para o resultado do indicador.

Outro fator que pode ter favorecido foi à localização dos empreendimentos. Enquanto a obra da construtora B localizava-se no bairro do Pina, próximo ao Shopping Rio Mar que ainda está em construção, a obra da construtora A localizava-se num bairro extremamente procurado para residências e próximo ao centro da cidade, o bairro do Espinheiro.

Como estratégias de marketing, estas também utilizavam os principais recursos de divulgação, como internet, banners, folderes e televisão, mas vale salientar que, para a construtora $B$, não foi muito necessária estas estratégias, pois a maior divulgação foi realizada pelos comentários boca a boca.

As principais práticas identificadas neste indicador resumiram-se a um estudo de mercado na fase de projeto dos empreendimentos, bem como das características mais procuradas pelos compradores. No estudo de mercado, foram consideradas variáveis como tipo de cliente, órgãos financiadores, faixa de preço, localização e caracterização do empreendimento; sendo estas analisadas como variáveis dependentes uma das outras, a fim de intensificar o ritmo de vendas da construtora.

\subsection{Geração de resíduos de tijolos/blocos}

A alvenaria de um sistema construtivo pode ser conceituada como sendo o sistema de paredes e muros, ou obras similares, executadas com pedras, com tijolos cerâmicos, blocos de concreto, cerâmicas e silicocalcário, assentados com ou sem argamassa de ligação (ZULIAN; DONÁ; VARGAS, 2002).

As paredes de vedação em alvenaria são assim denominadas por não possuírem função estrutural, restringindo-se a vedação, isto é, "tampar vãos". Sendo os elementos mais utilizados, atualmente, na construção de edifícios, estes se inter-relacionam com outros elementos da alvenaria, como por exemplo, revestimentos, esquadrias, instalações, impermeabilizações e estrutura, podendo influenciar até $40 \%$ do custo total da obra (PINHO, 2010).

As vedações em alvenaria também são responsáveis por, aproximadamente, $17 \%$ de desperdício de tijolos/ blocos e $115 \%$ de desperdício de argamassa. Nesse sentido, a racionalização das alvenarias de vedação é destacada como fundamental para o atendimento dos requisitos de custo, prazo e qualidade (PINHO, 2010).

O índice de geração de resíduos de tijolos/blocos representa o valor de benchmarking obtido pela empresa A e caracterizado a seguir.

O projeto de alvenaria é uma ferramenta bastante utilizada, atualmente, nas vedações verticais e de essencial importância para a qualidade do produto, sendo responsável pela coordenação e compatibilização das disciplinas de projeto, modulação e ajuste dimensional das paredes, detalhamento técnico do processo de alvenaria e projeto de produção.

Diante disto, o questionário de caracterização do benchmarking do indicador em questão continha uma descrição do projeto de alvenaria, a fim de identificar as singularidades da empresa A, que levaram ao menor índice de geração de resíduos de tijolos/blocos.

As singularidades encontradas foram à adoção de semi blocos e compensadores do bloco 9x19x39 cm próximo ao encunhamento, amarração de paredes e nas aberturas de portas e janelas, ao invés da quebra de blocos inteiros para a mesma finalidade. Além disso, a adoção da planta de numeração de paredes, da paginação da parede em elevação 
e da planta de primeira e segunda fiada permitiram a melhor identificação das mesmas e prevenção de retrabalhos em caso de erros.

A elevação de cada parede foi feita separadamente, sobrepondo-se os projetos de instalações e contemplando os tipos de blocos, a quantidade de cada um, as dimensões das aberturas, a posição de vergas e contravergas, o posicionamento de eletrodutos e caixas de luz, telefone, antena, internet e outros, além dos detalhes de amarração de paredes e entre as paredes e a estrutura.

Quanto ao recebimento, os blocos, assim que chegavam ao canteiro de obras eram armazenados diretamente no estoque definitivo semi enterrado, não havendo estoque intermediário, com o intuito de desobstruir o corredor de acesso à obra.

Segundo Pinho (2010), a utilização de estoque intermediário é uma característica típica do processo construtivo tradicional e que só aumenta a possibilidade de quebras dos blocos. A não utilização deste estoque intermediário pôde ter contribuído para o resultado de benchmarking obtido pela construtora A.

Além disso, o fato dos blocos serem palletizados e transportados em carrinhos porta mini pallets reduziu o contato do bloco com a umidade do chão e otimizou o tempo de transporte dos mesmos até o pavimento, necessitando de menos força empregada da mão-de-obra.

\section{Considerações finais}

Apesar de algumas práticas aqui mencionadas já serem vivenciadas na rotina de uma construtora, a identificação delas pelo processo de benchmarking permitiu o fortalecimento dos conceitos já aplicados e o aprimoramento em algumas situações.

A elaboração dos questionários de caracterização do benchmarking trouxe não só o detalhamento das práticas adotadas pelas empresas participantes, mas o conhecimento abrangente das variáveis do indicador e o acompanhamento dos processos envolvidos com o mesmo.

O fato dos questionários serem respondidos, pessoalmente, em entrevista realizada com os responsáveis pelo setor envolvido, facilitou na identificação das melhores práticas, bem como a percepção da importância do indicador para construtora.

As contribuições geradas foram relevantes para a finalização do processo de benchmarking, iniciado em pesquisas anteriores e coordenado pelo mesmo grupo de pesquisa, o POLITECH. Estas possibilitaram a definição de características de referência para o setor da construção civil em Recife/PE, a fim de planejar, controlar e melhorar, continuamente, seus processos.

\section{Referências}

[1] ASSOCIAÇÃO BRASILEIRA DE NORMAS TÉCNICAS. ABNT NBR 7200: Execução de revestimento de paredes e tetos de argamassas inorgânicas - Procedimento. Rio de Janeiro, 1998.

ABNT NBR ISO 9001: Sistema de gestão da qualidade - Requisitos. Rio de Janeiro, 2000, 21p.

ABNT NBR 13529: Revestimento de paredes e tetos de argamassas inorgânicas. Rio de Janeiro, 1995.

ABNT NBR 14081: Argamassa colante industrializada para assentamento de placas cerâmicas Requisitos. Rio de Janeiro, 2005.

Ações para diminuição da geração de resíduos na indústria de revestimentos cerâmicos e a reciclagem das "raspas". Parte I: resultados preliminares. Disponível em: $<$ http://www.bvsde.paho.org/bvsacd/cd48/raspas.pdf $>$. Acesso em: 06 de jul. de 2011.

[2] CARDOSO, A. L. Políticas de recuperação de crédito de longo prazo em situação de inadimplência com direcionamento para a agência de fomento: o caso BADESC. 2005. Monografia (Gradução), Universidade do Vale do Itajaí, São José.

[3] CAMARGO, A. Minas de Entulho. Téchne, São Paulo, $\mathrm{n}^{\circ}$ 15, ed. PINI, mar/abr.1995. CASTRO, I. R. Grandes mudanças no marketing das construtoras e incorporadoras imobiliárias. Artigonal, diretório de artigos gratuitos. Disponível em: $<$ http://www.artigonal.com/marketing-e-publicidadeartigos/grandes-mudancas-no-marketing-das-construtoras-eincorporadorasimobiliarias-379513.html >.Acesso em: 15 ago. 2011.

[4] Chiavenato, I. Teoria Geral da Administração. São Paulo, 2004.

[5] COSTA, D. B. Diretrizes para concepção, implementação e uso de sistemas de indicadores de desempenho para empresas da construção 
civil. 2003. Dissertação (Mestrado em Engenharia Civil), Universidade Federal do Rio Grande do Sul, Porto Alegre.

[6] DALL'INHA, G. R. A influência das práticas e das políticas de recursos humanos sobre o absenteísmo e a rotatividade: um estudo de caso. 2006. Dissertação (Mestrado em Engenharia de Produção), UniversidadeFederal de Santa Catarina, Florianópolis.

FREITAS, C. L. Notas de aula da disciplina Engenharia Ambiental. Escola Politécnica da Universidade de Pernambuco, 2011.

GAEDE, L. P. F. Gestão dos resíduos da construção civil no município de Vitória - ES e normas existentes. 2008. Monografia (Curso de Especialização em Construção Civil) - Escola de Engenharia, Belo Horizonte.

Incorporadora usa mediação para resolver problemas de inadimplência. Portal VGV. Disponível em: <http://www.portalvgv.com.br/site/incorporadora-usamediacao-para-resolver-problemasde-inadimplencia/>. Acesso em: 15 ago. 2011.

LANTELME, E. M. V. Proposta de um sistema de indicadores de qualidade e produtividade para construção civil. 1994. Dissertação (Mestrado em Engenharia Civil), Universidade Federal do Rio Grande do Sul, Porto Alegre.

[7] LIMA JR., J. M.; VALCÁRCEL, A. L.; DIAS L. A. OIT - Secretaria Internacional do Trabalho. Brasília, 2005. Disponível em: $<$ http://www.oit.org.pe/WDMS/bib/publ/doctrab/dt_200_port.pdf $>$. Acesso em: 13 jul. 2011.

[8] LORDSLEEM JR., A. C.; PINHO, S. A. C. Perdas de Tijolos/Blocos e argamassa da alvenaria de vedação: metodologia de coleta e análise de resultados. In: VII Encontro Tecnológico da Engenharia Civil e Arquitetura - ENTECA, Maringá, 2009. Minas Gerais. Sindicato da Indústria da Construção Civil (SINDUSCON - MG). Programa Qualimat SINDUSCON - MG. Placas cerâmicas para revestimento. Belo Horizonte, 2009. 24p. Disponível em: < http://pt.scribd.com/doc/54080996/Placas-Ceramicas-Para-Revestimento $>$. Acesso em: 06 de jul. 2011.
[9] OLIVEIRA, F. A. L. Argamassa industrializada: vantagens e desvantagens. 2006. Monografia (Graduação em Engenharia Civil) - Universidade Anhembi Morumbi, São Paulo.

PEREIRA, E. A. Diagnóstico dos problemas de gestão de obras habitacionais de interesse social em empresas privadas. Monografia (Curso de Especialização em Construção Civil), Escola de Engenharia UFMG, Belo Horizonte, 2008.

[10] PINHO, S. A. C. Avaliação da racionalização da tecnologia construtiva das vedações em alvenaria através de indicadores de desempenho. 2010. Monografia (Graduação em Engenharia Civil), Escola Politécnica de Pernambuco, Universidade de Pernambuco, Recife.

[11] RESENDE, M. M.; MELHADO, S. B.; MEDEIROS, J.S. Gestão da qualidade e assistência técnica aos clientes na construção de edifícios. In: V Congresso de Engenharia Civil, 2002, Juiz de Fora - MG.

RIBEIRO, M. O marketing das construtoras na venda de imóveis. IRC - Inácio Rodrigo de Castro. Disponível em: $<\mathrm{http}$ //inaciorodrigodecastro.com.br/o-arketing-dasconstrutoras-na-vendade-imoveis >.Acesso em: 15 ago. 2011.

[12] SOUZA, R.; MEKBEKIAN, G.; SILVA, M. A. C.; LEITÃO, A. C. M. T.; SANTOS, M. M.; Sistema de Gestão da Qualidade para Empresas Construtoras. São Paulo: SINDUSCON, 1994 . 